\title{
Oil spill boom modelling by the finite-element method
}

\author{
F. Muttin \\ Engineering School EIGSI La Rochelle, France
}

\begin{abstract}
During an oil-spill crisis, emergency action plans define priority locations on coastal zones to be protected by floating booms. Estuaries, fisheries, oyster production, and water supply are some of the most concerned examples. An oilspill boom is a long floating structure, the boom length can be as long as $1 \mathrm{~km}$. A boom is used to deviate or to stop a floating pollution. The strategy to be adopted (deviative or stopping) depends on the current velocity. The sea current velocity and direction are variable in a coastal zone and it can depend on fluvial or tide flow. The variability of the environmental conditions increases the complexity of the mechanical problem. Another difficulty of a boom contingency plan comes from the definition of the adapted boundary conditions. Sea depth and coastal morphology must be compatible with the boom mooring devices: anchor, pile, and fixed point. This paper presents two numerical models named FORBAR and SIMBAR. FORBAR uses a 1D cable equation which permits to handle the boom curve on the sea surface. SIMBAR uses a 3D membrane finite-element which permits to characterize the submarine boom skirt angle. These numerical models are able to give as much mechanical information as required to optimize the system. A comparison between the two numerical models, 1D model (FORBAR) and 3D model (SIMBAR), is shown in the case of the Elorn river (Brittany, France) contingency plan.
\end{abstract}

Keywords: spilled oil, containment, floating boom, coastal waters.

\section{Introduction}

A floating boom is a flexible structure moored on a coastal zone [1]. A boom is composed of a floating device (inflatable tube) and an immerged flexible skirt. 
At the bottom of the skirt, a chain permits to weigh vertically on the skirt and to attract the longitudinal tension of the boom.

Estuaries and rias are coastal sites that are difficult to protect from oil pollution. It is a consequence of the high current velocity present in these coastal zones. The current velocity is a major effect for the oil containment efficiency of boom and for the external load on booms.

A boom plan is composed of several boom sections. The mooring device of a boom plan is composed of mooring lines, buoyancy coffers and attachments on the shore at its extremities. The mooring line and buoyancy coffers are attached at the junction of adjacent boom sections.

In this introduction, we will now present the different geometries adopted in a boom plan to deviate or to stop oil floating pollution. Figure 1 presents a straight boom plan in an estuary.

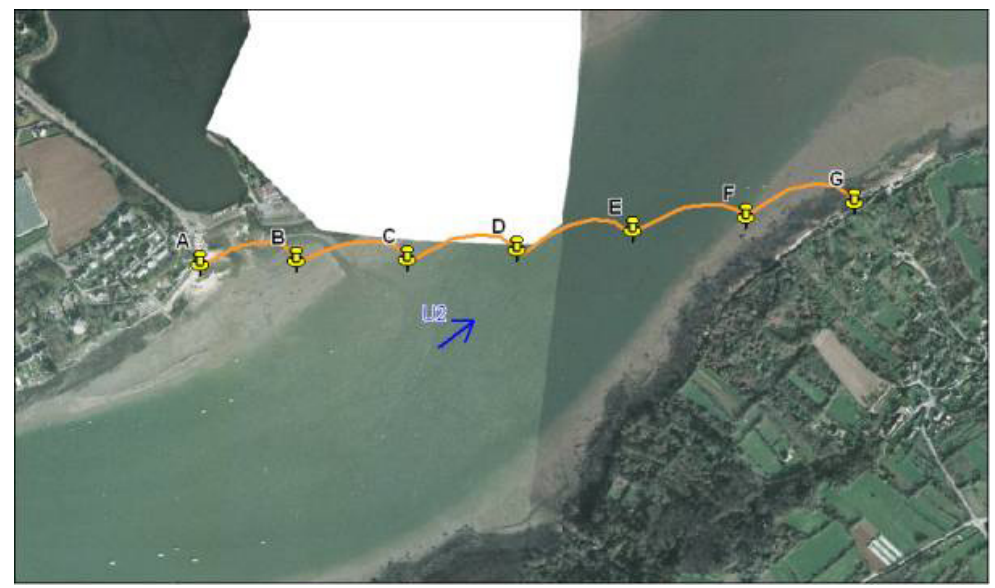

Figure 1: Straight boom plan with an angulation, the Elorn river (Brest, Brittany, France).

This boom plan has an angulation with the current direction. It permits to reduce the normal current velocity with respect to the boom direction. As a consequence, it increases the boom efficiency and reduces the boom mechanical stress. The improvement of such oil boom plan results from a numerical model. A model permits to evaluate an innovative boom plan conception. As example we can cite the boom skirt height, the mooring line length, the boom elasticity.

Figure 2 shows a boom plan in a river, where the current takes a fixed direction with respect to the boom. Here again, a model can be used to improve the angle between the two boom sections and the current. The model may give the boom tension on its mooring line and its fixation on the shore.

Figure 3 shows an emergency boom plan in a complex coastal zone, where the bathymetry and the water depth are variable. The tide effect reduces locally the water depth. Consequently to avoid the boom grounding, two supplementary mooring lines are added. It permits to reduce locally the avoiding radius of the 
boom, indicating locally the size of its displacement zone on the sea surface. Note that a door permits to open temporary the maritime circulation. The Lambert GIS geographical co-ordinates system is used to define the boom plan anchorage extremities [2]. The French POLMAR plan uses the Lambert geodesic systems, IGN [2]. The conversion from this co-ordinate system to other standard co-ordinate systems can be found in [2].

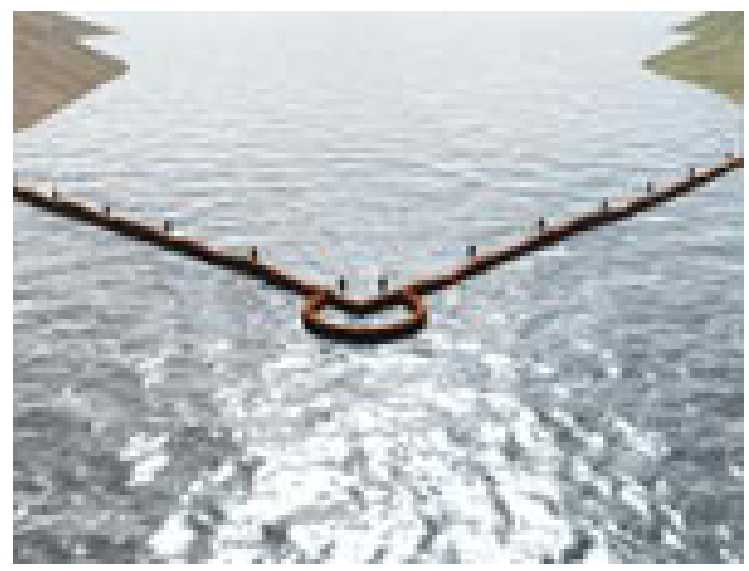

Figure 2: $\quad \mathrm{V}$ boom plan in a river, with flow in a single direction, Triskel $\mathrm{C}$.

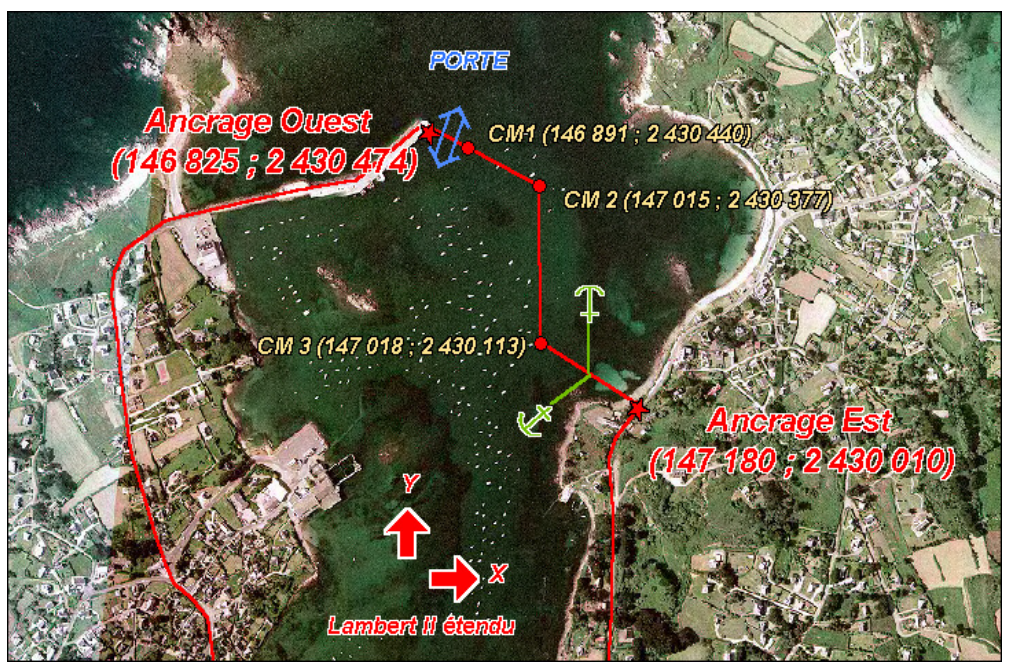

Figure 3: $\quad \mathrm{Z}$ boom plan of the Diben site (Brittany, France) POLMAR (C.

This research is done in the collaborative project BAR3D [3] with "Laboratoire National Hydraulique et Environnement - EDF" which develops a numerical model for the oil and the water flows around a boom section [4]. The 
CEDRE “Centre de Documentation de Recherche et d'expérimentations sur les pollutions accidentelles des Eaux" provides its expertise in antipollution. The TOTAL company will made an exercise on the basis of a result from the model. The test is scheduled in 2008. The CETMEF "Centre d'Etudes Maritimes et Fluviales" is the French administration which helps the research orientation by providing their knowledge on booms.

To improve the different geometries of a boom plan, such as those presented, a numerical model is valuable. In this paper two numerical models are presented. To reduce the computational time, we may use a simplified model using a curvilinear continuum (cable) instead of a 3D membrane finite-element mesh. Simple model and evolved model give complementary information which permits to handle the boom and the plan performances. The two models FORBAR and SIMBAR are now presented from the theoretical point of view.

\section{Boom theory}

Boom theory from the structural point of view concerns a mono-dimensional model and a 3D model. The mono-dimensional model is a chain (1D) imbedded on the sea surface (2D), Lafon [5]. The 3D model is a curved membrane (3D) imbedded in the vicinity of the sea surface. It is composed of a floating part, and an immerged part, Muttin et al. [6].

On one hand, the equilibrium on the sea surface of a flexible cable can be written in the following way

$$
\frac{d(T \vec{t})}{d s}+P \vec{t}+Q \vec{n}=0
$$

Where $\mathrm{T}$ is the cable tension, $\mathrm{P}$ is the tangential hydrodynamic force, $\mathrm{Q}$ is the normal hydrodynamic force, and $\mathrm{s}$ is the curvilinear co-ordinate along the cable. It considers along the vertical direction the equilibrium between the cable selfweight, the Archimedes force, and the hydrodynamic pressure.

On the other hand, the equilibrium of a curved membrane can be written using a thin-shell formulation using the covariant co-ordinates of the membrane surface, and the minimisation of its total mechanical energy e defined by

$$
e=\frac{1}{2} \int_{\omega} \operatorname{tr}(\sigma x) d \omega-\int_{\omega+v}(f v) d(\omega+v)
$$

Where $\sigma$ is the stress tensor, $\mathrm{x}$ is the strain tensor, $\mathrm{f}$ is the applied load, and $v$ is the membrane displacement. The non-linear membrane strain tensor $\mathrm{x}$ measures the half difference between the metric tensor $\mathrm{a}^{*}$ of the deformed membrane surface $\omega+v$ and the metric tensor a of the initial membrane surface $\omega$,

$$
x=1 / 2\left(a^{*}-a\right)
$$

The applied load $\mathrm{f}$ is composed of a pneumatic pressure (boom float), a gravity force (self-weight), a hydrodynamic pressure (sea current) and a hydrostatic pressure (Archimedes force). 
We present now the generation of a finite-element mesh adapted to a specific geometry of a boom plan.

\section{Boom as a 3D mesh of membrane finite elements}

The numerical modelling must be adapted to different coastal sites, and different boom plan geometries: straight (figure 1), Y curve (figure 2), Z curve (figure 3). A ' $\mathrm{V}$ ' geometry of a boom plan can be constructed using two parameters of the section: the cord length $\mathrm{L}_{1}$ and the ' $\mathrm{V}$ ' height $\mathrm{P}$. By means of two linear shape functions $\mathrm{N}_{1}$ and $\mathrm{N}_{2}$, a ' $\mathrm{V}$ ' boom can be constructed by the transformation of a straight boom mesh defined along the s direction.

$$
\begin{aligned}
\mathrm{Y} & =\mathrm{N}_{1}(\mathrm{~s}), \mathrm{s} \in\left[0, \mathrm{~L}_{1}\right] \\
\mathrm{Y} & =\mathrm{N}_{2}(\mathrm{~s}), \mathrm{s} \in\left[\mathrm{L}_{1}, \mathrm{~L}\right] \\
\mathrm{N}_{1}\left(\mathrm{~L}_{1}\right) & =\mathrm{N}_{2}\left(\mathrm{~L}_{1}\right)=\mathrm{P}
\end{aligned}
$$

The equation (5) permits to have a continuous definition of the ' $\mathrm{V}$ ' boom. The idea is to transform a straight mesh so that it takes the required geometry. Note that the transformation (3)-(5) of the straight mesh defined on $[0, \mathrm{~L}]$ is not an isometry. A ' $\mathrm{Z}$ ' boom plan mesh can be constructed by using the same approach and three shape functions.

Note that from the operational point of view the shape values $\mathrm{L}_{1}$ and $\mathrm{P}$ are adjusted so that the angle between the sea current and the boom correspond to the limit of the boom efficiency.

The length of a boom section can be higher than the boom cord. This one is the length on the sea surface where the oil is stopped or deviated. The higher length of the boom section compared to the boom cord permits to reduce the mechanical stress in the boom. As consequence the curvature of the boom section is higher. To include this effect in a straight boom finite-element mesh we introduced a negative pre-stress in the straight mesh. It is defined by applying a scaling $\mathrm{k}$ on the longitudinal component $\mathrm{a}_{11}$ of the initial metric tensor a of the membrane surface. This scaling is defined by

$$
\widetilde{a}_{11}=k a_{11} \quad k \succ 1
$$

where $\mathrm{k}$ is the boom length divided by the cord length.

We will now present the comparison of the two models FORBAR and SIMBAR which has been applied to the straight boom plan of the Elorn river.

\section{Results and discussion}

This section focuses on the comparison of the two models, FORBAR and SIMBAR on the straight boom of the Elorn river. The FORBAR model is named ANCRAGE when it concerns the mooring lines of the boom plan.

The FORBAR model of the Elorn river uses 6 boom sections, as shown in figure 1. The length of the boom cord and the boom sections are given in the following table. The SIMBAR project uses for the Elorn boom the same length $171.2 \mathrm{~m}(\mathrm{k}=1)$. 
Table 1: $\quad$ Boom cord length and boom section length of the Elorn river FORBAR plan.

\begin{tabular}{|c|c|c|c|}
\hline Boom section & $\begin{array}{c}\text { Boom cord Length } \\
(\mathrm{m})\end{array}$ & $\begin{array}{c}\text { Boom section } \\
\text { length }(\mathrm{m})\end{array}$ & Pre-stress factor \\
\hline $\mathrm{AB}$ & 180 & 200 & 1.11 \\
\hline $\mathrm{BC}$ & 209 & 230 & 1.10 \\
\hline $\mathrm{CD}$ & 208 & 230 & 1.11 \\
\hline $\mathrm{DE}$ & 220 & 240 & 1.09 \\
\hline $\mathrm{EF}$ & 216 & 240 & 1.11 \\
\hline $\mathrm{FG}$ & 205 & 230 & 1.12 \\
\hline
\end{tabular}

We notice here a main difference between the data used in the two models. The FORBAR data contains a negative pre-stress of the boom sections, while SIMBAR uses straight boom sections in their initial states. Consequently the boom tension may be higher in the SIMBAR result.

The FORBAR model uses for the sea current in the Elorn estuary a SHOM data [7]. The current vector magnitude is $U=0.41 \mathrm{~m} / \mathrm{s}$ with the components $U_{X}$ $=0.33$ and $\mathrm{U}_{\mathrm{Y}}=0.25$ with respect to the computational grid. The SIMBAR model uses a current map on each Elorn boom section resulting from a TELEMAC computation of the Brest coastal sea. The current vector magnitudes and its components are indicated on the following table. The values indicated correspond to the time number 7 considered in the SIMBAR project [8].

Table 2: $\quad$ Current vectors along the Elorn boom plan SIMBAR.

\begin{tabular}{|c|c|c|c|}
\hline Mooring point & $\begin{array}{c}\text { Velocity magnitude } \\
(\mathrm{m} / \mathrm{s})\end{array}$ & $\begin{array}{c}\text { U component } \\
(\mathrm{m} / \mathrm{s})\end{array}$ & $\begin{array}{c}\text { V component } \\
(\mathrm{m} / \mathrm{s})\end{array}$ \\
\hline $\mathrm{A}$ & 0.05 & 0.05 & 0.00 \\
\hline $\mathrm{B}$ & 0.14 & 0.14 & 0.04 \\
\hline $\mathrm{C}$ & 0.26 & 0.24 & 0.12 \\
\hline $\mathrm{D}$ & 0.40 & 0.31 & 0.25 \\
\hline $\mathrm{E}$ & 0.39 & 0.25 & 0.30 \\
\hline $\mathrm{F}$ & 0.24 & 0.13 & 0.21 \\
\hline $\mathrm{G}$ & 0.06 & -0.04 & 0.04 \\
\hline
\end{tabular}

We mention that the FORBAR data uses a constant sea current along the boom plan, while the SIMBAR data depends of the position on the boom.

The FORBAR model of the Elorn river uses the boom references Baléar 335 and Baléar 333 bis. These references are large boom with a floating device. The SIMBAR model uses a standard boom reference. The boom float diameter is $55 \mathrm{~cm}$, and the boom skirt height is $75 \mathrm{~cm}$.

The results of the following table come from the FORBAR model and from the SIMBAR model. The FORBAR model solves the cable equation (1). The SIMBAR model is based on the membrane equation (2).

The principal difference between the two models is on the boom tension. That difference can be interpreted as the consequence of the difference in the boom 
section length. The negative pre-stress considered in the FORBAR model permits to reduce significantly the boom tension, while the straight boom mesh used in the SIMBAR model corresponds to a maximum of the boom tension.

Table 3: $\quad$ Boom tension and containment efficiency from FORBAR and SIMBAR.

\begin{tabular}{|c|c|c|c|c|c|c|}
\hline $\begin{array}{l}\text { Boom } \\
\text { section }\end{array}$ & $\begin{array}{c}\text { Skirt } \\
\text { height } \\
\text { FORBAR } \\
\text { (m) }\end{array}$ & $\begin{array}{c}\text { Skirt } \\
\text { height } \\
\text { SIMBAR } \\
\text { (m) }\end{array}$ & $\begin{array}{c}\text { Boom } \\
\text { tension } \\
\text { FORBAR } \\
(\mathrm{T})\end{array}$ & $\begin{array}{l}\text { Boom } \\
\text { Chain } \\
\text { tension } \\
\text { SIMBAR } \\
\text { (T) }\end{array}$ & $\begin{array}{c}\text { Containment } \\
\text { criteria } \\
\text { FORBAR: } \\
\text { Oil leakage } \\
(\%)\end{array}$ & $\begin{array}{l}\text { Containment } \\
\text { criteria } \\
\text { SIMBAR: } \\
\text { Skirt angle } \\
\left(^{\circ}\right)\end{array}$ \\
\hline $\mathrm{AB}$ & \multirow{3}{*}{0.85} & \multirow{3}{*}{0.75} & 0.575 & 5.33 & 21 & -0.0576 \\
\hline $\mathrm{BC}$ & & & 0.744 & 5.34 & 21 & -0.115 \\
\hline $\mathrm{CD}$ & & & 0.626 & 5.33 & 19 & -2.01 \\
\hline $\mathrm{DE}$ & \multirow{3}{*}{0.87} & \multirow{3}{*}{0.75} & 0.621 & 5.33 & 14 & -7.68 \\
\hline $\mathrm{EF}$ & & & 0.605 & 5.31 & 17.7 & -10.9 \\
\hline FG & & & 0.537 & 5.33 & 18 & -7.58 \\
\hline
\end{tabular}

Table 3 indicates also the oil containment criteria used by the FORBAR and SIMBAR models. The FORBAR efficiency criteria is the oil hydrodynamic Lee criteria [9], while the criteria used by SIMBAR is the vertical angle of the boom skirt [8]. The Lee criteria is based on a fluid flow approach using oil density and current velocity. The SIMBAR criteria is based on a fluid/structure approach. From the operational point of view, the skirt angle threshold value is $\pm 10^{\circ}$ in presence of light oil pollutant. The efficiency criteria is more uniform in the FORBAR result, while the SIMBAR result indicates less efficiency of the boom plan section $n^{\circ} E F$. The difference of the inefficiency location of the Elorn plan may be explained as a consequence of the uniform current velocity considered in the FORBAR model, while the SIMBAR model uses a non-constant current map, indicating stronger current amplitude in the vicinity of the point $\mathrm{D}$ (table 2).

Table 4: $\quad$ Mooring lines considered in ANCRAGE and SIMBAR.

\begin{tabular}{|c|c|c|c|c|}
\hline $\begin{array}{c}\text { Mooring } \\
\text { point }\end{array}$ & $\begin{array}{c}\text { ANCRAGE } \\
\text { Mooring line } \\
\text { length (m) }\end{array}$ & $\begin{array}{c}\text { SIMBAR } \\
\text { Mooring line } \\
\text { length (m) }\end{array}$ & $\begin{array}{c}\text { ANCRAGE } \\
\text { Maximal } \\
\text { water depth } \\
(\mathrm{m})\end{array}$ & $\begin{array}{c}\text { SIMBAR } \\
\text { water depth } \\
\text { at time } \\
\text { number } 7(\mathrm{~m})\end{array}$ \\
\hline $\mathrm{A}$ & $/$ & 7.2 & $/$ & 0.1 \\
\hline $\mathrm{B}$ & 12 & 13.6 & 7.1 & 1.7 \\
\hline $\mathrm{C}$ & 20 & 23 & 16.1 & 3.7 \\
\hline $\mathrm{D}$ & 50 & 36.7 & 6.6 & 6.8 \\
\hline $\mathrm{E}$ & 20 & 20.8 & 4.5 & 10.7 \\
\hline $\mathrm{F}$ & 15 & & $/$ & 5.4 \\
\hline $\mathrm{G}$ & $/$ & & & \\
\hline
\end{tabular}


The following table shows the mooring line lengths of the Elorn boom plan, used in the ANCRAGE (FORBAR model), and in the SIMBAR model. A water depth data is equally indicated.

We note that the mooring line lengths $\mathrm{E}$ and $\mathrm{F}$ are higher in the SIMBAR model than in the ANCRAGE model, while it is the contrary for B-C-D. We note also that the maximum water depth is different in the two models and are located at different points. These differences may tell the difficulty to compare similar data on a large device (more than $1 \mathrm{~km}$ ) between terrestrial and maritime geographical information systems [10].

The mooring line tensions indicated in the following table are obtained from the ANCRAGE (FORBAR) model and the SIMBAR model. It concerns the mooring lines of the Elorn boom plan.

Table 5: $\quad$ Mooring lines tension from ANCRAGE and SIMBAR models.

\begin{tabular}{|c|c|c|}
\hline $\begin{array}{c}\text { Mooring } \\
\text { point }\end{array}$ & $\begin{array}{c}\text { ANCRAGE } \\
\text { Mooring line } \\
\text { tension (T) }\end{array}$ & $\begin{array}{c}\text { SIMBAR } \\
\text { Mooring line } \\
\text { tension (T) }\end{array}$ \\
\hline $\mathrm{A}$ & 0.287 & 0.210 \\
\hline $\mathrm{B}$ & 0.660 & 0.327 \\
\hline $\mathrm{C}$ & 0.685 & 0.164 \\
\hline $\mathrm{D}$ & 0.624 & 0.428 \\
\hline $\mathrm{E}$ & 0.613 & 0.690 \\
\hline $\mathrm{F}$ & 0.571 & 0.818 \\
\hline $\mathrm{G}$ & 0.268 & $/$ \\
\hline
\end{tabular}

Table 6: Tension on Buoyancy coffers from ANCRAGE and (SIMBAR in parenthesis).

\begin{tabular}{|l|c|c|c|c|c|}
\hline Buoyancy Coffer $^{\circ}$ & B & C & D & E & F \\
\hline Horizontal Force (T) & 0.66 & 0.685 & 0.624 & 0.613 & $\begin{array}{c}0.571 \\
(\mathrm{NA})\end{array}$ \\
\hline Tension on head (T) & 0.753 & 0.828 & 0.954 & 0.748 & $\begin{array}{c}0.665 \\
(\mathrm{NA})\end{array}$ \\
\hline Tension on anchor (T) & $\begin{array}{c}0.67 \\
(0.41)\end{array}$ & $\begin{array}{c}0.683 \\
(0.139)\end{array}$ & $\begin{array}{c}0.623 \\
(0.428)\end{array}$ & $\begin{array}{c}0.611 \\
(0.69)\end{array}$ & $\begin{array}{c}0.571 \\
(0.824)\end{array}$ \\
\hline Tension angle on & $\begin{array}{c}9.66^{\circ} \\
(\mathrm{NA})\end{array}$ & $\begin{array}{c}4.77^{\circ} \\
(\mathrm{NA})\end{array}$ & $\begin{array}{c}0^{\circ} \\
\left(18^{\circ}\right)\end{array}$ & $\begin{array}{c}1.55^{\circ} \\
\left(11^{\circ}\right)\end{array}$ & $\begin{array}{c}2.96^{\circ} \\
(\mathrm{NA})\end{array}$ \\
\hline anchor ( $\left.{ }^{\circ}\right)$ & $\begin{array}{c}11.25 \\
(0.52)\end{array}$ & $\begin{array}{c}18.48 \\
(3.77)\end{array}$ & $\begin{array}{c}44.83 \\
(11.2)\end{array}$ & $\begin{array}{c}18.56 \\
(14.1)\end{array}$ & $\begin{array}{c}14.15 \\
(6.42)\end{array}$ \\
\hline Avoiding radius (m) & $\begin{array}{c}0 \\
(0)\end{array}$ & $\begin{array}{c}16.50(0) \\
(0)\end{array}$ & $\begin{array}{c}0 \\
(0)\end{array}$ \\
\hline Sleeping length (m) & \multicolumn{2}{c|}{} & &
\end{tabular}

We note a difference between the two models. The difference in the mooring line tensions may result from the difference in the sea current data used in both 
models. We mention also that the difference in the boom section length considered in both models seems to have no effect in the transversal mooring line tensions.

Here follows the comparison between the ANCRAGE (FORBAR) and SIMBAR models concerning the buoyancy coffers and the mooring lines at each junction between adjacent boom sections. The sleeping length of a mooring line is the length of the mooring line in contact with the sea bottom. The SIMBAR results are indicated in parenthesis.

We note that several differences are observed between both models. The tension on anchor and the tension angle on anchor differ between both models. Moreover, the sleeping length of the mooring lines and the avoiding radius of the buoyancy coffers are different between the two models. That suggests that the given data used in both models must be more adjusted.

\section{Conclusion}

The main result issued from the comparison of the FORBAR results and the SIMBAR results on the Elorn boom plan, is that the longitudinal boom tension has a reduced agreement, while the transversal forces (mooring line, coffer traction) agreement is better.

The differences mentioned in the FORBAR and SIMBAR models results on the Elorn river boom plan indicate that several improvements must be made on the environmental conditions used in the plan, on the length of each boom sections (having a strong influence on the boom tension), and on the behaviour of the mooring lines to be taken into account.

The difference in the given data between two approaches based on FORBAR and SIMBAR illustrate the complexity of the boom plan problem taken in its real environment. The difference in the results issued from the two approaches results from the differences in the data and from the mechanical equations of the models. That suggests using these complementary models together to improve a boom plan.

\section{Acknowledgements}

This research is supported by the French Research Agency ANR, and ADEME, under grant $\mathrm{n}^{\circ}$ BAR3D/0694C0067, $\mathrm{n}^{\circ}$ ANR-06-ECOT-003-01. The author acknowledges the French framework, PRECODD, on Environmental Technologies and Sustainable Development. The network "Recherche et d'Innovation Technologique RITMER", "Pollutions Marines Accidentelles et leurs Conséquences Ecologiques" is gratefully acknowledged.

\section{References}

[1] Muttin, F., Guyot, F., Nouchi, S., Variot, B., Experimental Numerical and Optimisation Study of Oil Spill Containment Boom, Proc. of Coastal Environment including Oil Spill Studies, Oil Spill 2004 Conference, Alicante, Wessex Institute of Technology, p 421-430, 2004. 
[2] IGN, Transformation entre systèmes géodésiques en France Métropolitaine, http://www.ign.fr/telechargement/education/fiches/geodesie/coordonn\%C3 \%A9es.pdf, 1999/2004

[3] BAR3D project, http://bar3d.eigsi.fr

[4] Violeau, D., Buvat, C., Abed-Meraim, K., De Nanteuil, E., Numerical modelling of boom and oil spill with SPH, Coastal Engineering, Vol 54 (2007) 895-913.

[5] Lafon, F., Logiciel FORBAR de calcul de barrages flottants antihydrocarbures, EDF R\&D, Industrial Report $n^{\circ}$ HP-75/03/015/A, Chatou, France, June 2003.

[6] Muttin, F., Nouchi, S., Numerical Study of Oil Spill Containment Boom by the Finite-Element Method, Proc. of Eighth International Conference on Modelling, Monitoring and Management of Water Pollution, Water Pollution 2006 Conference, Bologna, Wessex Institute of Technology, pp. 245-254, 2006.

[7] SHOM, La Base de Données Marée et Courant du SHOM, http://www.shom.fr/

[8] SIMBAR projet, http://simbar.eigsi.fr

[9] Lee, C.M., Kang, K.H., Prediction of oil boom performance in currents and waves, Spill Science and Technology Bulletin, Vol 4 No 4 (1997) 257-266.

[10] Géo Littoral http://siglittoral.test.application.equipement.gouv.fr/ 